\title{
Ciglitazone, a new hypoglycaemic agent. 4 . Effect on pancreatic islets of C57BL/6J-ob/ob and C57BL/KsJ-db/db mice
}

\author{
A. R. Diani ${ }^{1}$, T.Peterson ${ }^{1}$, G.A. Sawada ${ }^{1}$, B. M. Wyse ${ }^{1}$, B.J. Gilchrist ${ }^{1}$, A. E. Hearron ${ }^{2}$ and A. Y.Chang ${ }^{1}$ \\ Diabetes and Gastrointestinal Diseases Research ${ }^{1}$ and Biostatistics ${ }^{2}$, The Upjohn Company, Kalamazoo, Michigan, USA
}

\begin{abstract}
Summary. Pancreases of treated and control male C57BL/6J$\mathrm{ob} / \mathrm{ob}$ and $\mathrm{C} 57 \mathrm{BL} / \mathrm{KsJ}-\mathrm{db} / \mathrm{db}$ mice were evaluated by qualitative and morphometric microscopic techniques to determine the effects of chronic ciglitazone treatment on the morphology of $\beta$ cells and surface area and number of pancreatic islets. The $\beta$ cells of treated ob/ob and $\mathrm{db} / \mathrm{db}$ mice displayed moderate to heavy granulation whereas most $\beta$ cells of untreated obese and diabetic mice were extensively degranulated. Although moderate proliferation of the rough endoplasmic reticulum and Golgi apparatus was evident in some $\beta$ cells of treated $\mathrm{db} / \mathrm{db}$ mice, both groups of treated $\mathrm{ob} / \mathrm{ob}$ and $\mathrm{db} / \mathrm{db}$ mice displayed an improved pattern of insulin synthesis and storage. In contrast, the $\beta$ cells of untreated ob/ob and $\mathrm{db} / \mathrm{db}$ mice were in a severe state of stress which was indicated by extensive hypertrophy of the rough endoplasmic reticulum, Golgi apparatus and mitochondria. Some $\beta$ cells of untreated $\mathrm{db} /$ $\mathrm{db}$ mice also displayed lysosome aggregates indicative of early stages of necrosis. Morphometric analysis revealed that the surface area of islets of treated $o b / o b$ mice was significantly smaller in comparison with that of untreated ob/ob mice. Since the surface area of islets of treated $\mathrm{C} 57 \mathrm{BL} / 6 \mathrm{~J}-$
\end{abstract}

$+/$ ? mice (lean littermates of ob/ob mice) was less than that of treated ob/ob mice, the progression of islet hypertrophy in the obese mice was probably arrested or attenuated but not to the level of the treated $+/$ ? mice. The number of pancreatic islets was significantly greater in treated than in untreated $\mathrm{db}$ / $\mathrm{db}$ mice. A majority of the islets of untreated $\mathrm{db} / \mathrm{db}$ mice were atrophic and consisted of acinar and endocrine cells whereas most of the islets of treated $\mathrm{db} / \mathrm{db}$ mice appeared to be intact and unremarkable. The results of this study suggest that ciglitazone is an effective hypoglycaemic agent which may directly or indirectly promote $\beta$-cell regranulation and an improved pattern of insulin synthesis and storage in $\mathrm{ob} / \mathrm{ob}$ and $\mathrm{db} / \mathrm{db}$ mice. However, in treated $\mathrm{db} / \mathrm{db}$ mice, there still was some evidence of stress in the $\beta$ cells. Overall, the prolonged treatment with ciglitazone also seemed to inhibit the hypertrophy of islets in ob/ob mice and protect the structural integrity and viability of islets in $\mathrm{db} / \mathrm{db}$ mice.

Key words: Ciglitazone, C57BL/6J-ob/ob mice, C57BL/KsJ$\mathrm{db} / \mathrm{db}$ mice, $\beta$-cell granulation, electron microscopy, rough endoplasmic reticulum, Golgi apparatus.
Ciglitazone, 5-(4-(1-methylcyclohexylmethoxy)benzyl)thiazolidine-2,4-dione, has been reported to function as a potent oral hypoglycaemic compound in obese, hyperglycaemic, insulin-resistant animal models, such as $\mathrm{C} 57 \mathrm{BL} / 6 \mathrm{~J}-\mathrm{ob} / \mathrm{ob}$ and $\mathrm{C} 57 \mathrm{BL} / \mathrm{KsJ}-\mathrm{db} / \mathrm{db}$ mice [1]. Biochemical investigations on the mechanism of action of ciglitazone have shown that it increases the basal rate of glucose metabolism, improves insulin binding and enhances the response to insulin in isolated fat pads of $\mathrm{ob} / \mathrm{ob}$ mice [2]. This drug also elevated the glucose disposal rate, increased the incorporation of radiolabelled glucose into hepatic lipid, glycogen and protein and significantly depressed gluconeogenesis in the obese mice [3]. Moreover, chronic treatment with ciglitazone displayed a marked effect on the pancreatic islets of ob/ob mice by promoting regranulation of the pancreatic $\beta$ cells [1]. On the basis of the latter findings, the current study was conducted to examine further the effects of prolonged administration of ciglitazone on the morphology of pancreatic islets in $\mathrm{ob} / \mathrm{ob}$ and $\mathrm{db} / \mathrm{db}$ mice by qualitative and morphometric microscopic analysis.

\section{Materials and methods}

\section{Animals (general background information)}

The male $\mathrm{C} 57 \mathrm{BL} / 6 \mathrm{~J}-\mathrm{ob} / \mathrm{ob}, \mathrm{C} 57 \mathrm{BL} / 6 \mathrm{~J}-+/$ ? (lean littermates of the $\mathrm{ob} / \mathrm{ob}$ mice) and C57BL/KsJ-db/db mice were obtained from Jackson Laboratories, Bar Harbor, Maine, USA. Each mouse was individually housed in a metabolic cage and administered Purina mouse chow and water ad libitum. Prior to initiation of study, blood was drawn from the orbital sinus and analyzed for baseline blood glucose and/or plasma insulin. The ob/ob, $+/ ?(7-8$ week-old $)$ and $\mathrm{db} / \mathrm{db}$ (6-7 week-old) mice selected for ciglitazone treatment received the drug admixed with pulverized Purina mouse chow. The dosage varied according to the body weight and food intake of each mouse. The remaining ob/ob, $+/$ ? and $\mathrm{db} / \mathrm{db}$ mice were designated as controls and received pulverized Purina mouse chow without ciglitazone. 


\section{Study 1 (morphometric evaluation of islet surface area of $C 57 \mathrm{BL} / 6 \mathrm{~J}-\mathrm{ob} / \mathrm{ob}$ and $-+/$ ? mice)}

Six treated and six untreated ob/ob and six treated and six untreated $+/$ ? mice were studied. The treated groups were given ciglitazone at an average daily dose of $100 \mathrm{mg} / \mathrm{kg}$ and $150 \mathrm{mg} / \mathrm{kg}$, respectively, for a period of 7 weeks. Since there was no hypoglycaemic effect at $100 \mathrm{mg} / \mathrm{kg}$, the higher dose was used in the $+/$ ? mice in an effort to reduce blood glucose levels. One untreated ob/ob, one untreated $+/$ ? and one treated $+/$ ? mouse died during the study. The animals were killed by exsanguination through the orbital sinus and blood was assayed for glucose levels.

Pancreatic tissue from the untreated and treated ob/ob and $+/$ ? mice was resected, fixed in Bouins', blocked in paraffin and serial-sectioned $(5 \mu \mathrm{m})$ on a rotary microtome (American Optics, Buffalo, New York, USA). The sections were adhered to coded slides and stained with Gomori's aldehyde-fuchsin. At $200 \mu \mathrm{m}$ intervals throughout the entire pancreas, a section of pancreas was examined under a brightfield microscope (Zeiss Photomicroscope III, Oberkochen, FRG). All islets per section were individually photographed on type 52 Polaroid film. The surface area $\left(\mu \mathrm{m}^{2}\right)$ of each islet was measured by tracing the perimeter with a cursor on a Zeiss Videoplan digitizing tablet. The average number of islets measured was 300 (range 133-727) for each $\mathrm{ob} / \mathrm{ob}$ mouse and 54 (range 21-97) for each $+/$ ? mouse.

\section{Study 2 (ultrastructure of $\beta$ cells of C57BL $6 \mathrm{~J}$-ob/ob mice)}

Six treated and six untreated $\mathrm{ob} / \mathrm{ob}$ mice were studied. The treated mice received ciglitazone at an average daily dose of $100 \mathrm{mg} / \mathrm{kg}$ body weight for a period of 6 weeks. Two of the untreated ob/ob mice died during the study. At termination, all animals were exsanguinated through the orbital sinus and the blood was assayed for glucose and insulin. Pancreases were excised and divided into duodenal and splenic regions. A portion of the pancreatic tissue from both regions was utilized for electron microscopy and the remaining tissue for insulin extraction and assay. The pancreatic insulin content was obtained by averaging the values of the duodenal and splenic regions.

Pancreatic samples from the duodenal and splenic regions were individually minced, immersion-fixed in $2.5 \%$ glutaraldehyde $(0.15 \mathrm{~mol} / 1$ phosphate buffer $)$, dehydrated in graded alcohols and embedded in epon-araldite for electron microscopy. Each block was coded and cut into thick sections $(1 \mu \mathrm{m})$ by a MT-2B ultramicrotome (Dupont Sorvall, Newton, Connecticut, USA). The sections were stained with toluidine blue and examined under a Zeiss Photomicroscope III for the presence of islet tissue. Ultrathin silver sections $(80-90 \mathrm{~nm})$ of the islet tissue were cut on a MT-5000 ultramicrotome (Dupont Sorvall), collected on grids and stained with uranyl acetate and lead citrate. Each islet was examined and photographed under a Philip's 301 electron microscope (Model 301, Philips Electronic Instruments, Eindhoven, The Netherlands). Particular attention was directed to the granule population, Golgi apparatus, rough endoplasmic reticulum and mitochondria of the $\beta$ cells. At least two islets from the splenic region and one islet from the duodenal region were examined.

\section{Study 3 (Light and electron microscopy of pancreatic islets of C $57 B L / K s J-d b / d b$ mice)}

The treated mice were given ciglitazone at an average daily dose of $122 \mathrm{mg} / \mathrm{kg}$ body weight for 9 weeks. The dosage was raised to $>$ $100 \mathrm{mg} \cdot \mathrm{kg}^{-1} \cdot$ day $^{-1}$ during the study in an attempt to obtain normal blood glucose levels. Blood glucose was monitored at weekly intervals. At termination the five treated and seven untreated $\mathrm{db} / \mathrm{db}$ mice were exsanguinated through the orbital sinus and blood was analyzed for glucose and plasma insulin levels. The whole pancreas was resected and divided into the duodenal and splenic regions. Portions from both regions were utilized for light and electron microscopy and extraction and assay of insulin as described in Study 2. Some pancreatic tissue from the duodenal and splenic areas of each $\mathrm{db} / \mathrm{db}$ mouse was fixed in Bouin's and blocked in paraffin for light microscopic analysis, the remainder was fixed and prepared for electron microscopy as described in Study 2.

The paraffin blocks were serial-sectioned $(5 \mu \mathrm{m})$ and the slides were stained alternately, one with haematoxylin and eosin for routine morphological survey, the next with Gomori's aldehyde-fuchsin to study $\beta$ cell granulation. All slides were examined under a Zeiss Photomicroscope III and the highest quality aldehyde-fuchsin section (per duodenal and splenic region) was selected for photography. Each islet in these sections was photographed on Kodak Ektachrome film (ASA 200). Each colour slide (islet) was coded and examined blindly in a slide projector (Kodak Ektagraphic 260) for $\beta$-cell granulation as defined by the aldehyde-fuchsin stain. Islets were also examined for the presence or absence of exocrine cells within the endocrine tissue. Due to the small number of islets in some tissue sections, particularly those of untreated animals, and/or the lack of any discernible pattern of $\beta$-cell granulation or degranulation in either duodenal or splenic regions of an individual pancreas, the two regions were pooled for each animal. The mean number of islets evaluated for untreated and treated $\mathrm{db} / \mathrm{db}$ mice was 5 (range 2-8) and 19 (range 10-27) respectively. The mean percentage of granulated islets as well as islets with exocrine cells was calculated for each animal.

The epon-araldite blocks of pancreas (duodenal and splenic region) from each animal were sectioned and examined as described in Study 2.

\section{Study 4 (estimation of pancreatic islet number in $C 57 B L / K s J-d b / d b$ mice)}

The treated mice were administered ciglitazone at a daily dose of $164 \mathrm{mg} / \mathrm{kg}$ for 20 weeks. The dosage was elevated to $>100 \mathrm{mg}$. $\mathrm{kg}^{-1} \cdot$ day $^{-1}$ in an attempt to render normal the blood glucose levels of the treated mice. Blood glucose was evaluated at weekly intervals. At termination six treated and six untreated animals were bled through the orbital sinus and the blood was assayed for glucose. The entire pancreas from each of the six untreated and six treated mice was fixed, sectioned and stained as described in Study 1. At $200 \mu \mathrm{m}$ intervals throughout the entire pancreas, a section was studied under a Zeiss Photomicroscope III and all islets (per section) were counted. The total quantity of counted islets per animal was obtained by summation of islet number from each of the individual tissue sections.

\section{Assays}

Blood was drawn from the orbital sinus of each animal in the nonfasted state and glucose was measured fluorometrically in an autoanalyzer [4]. Immunoassay was used for plasma insulin estimation [5]. Extraction and radioimmunoassay of insulin from the pancreas was described previously [6].

\section{Chemicals}

Ciglitazone was obtained from Takeda Chemical Industries, Osaka, Japan. ${ }^{125}$ I-insulin was purchased from New England Nuclear, Boston, MA, USA.

\section{Statistical analysis}

All biochemical and morphological data are reported as mean \pm SEM. The blood glucose and plasma and pancreatic insulin data were analyzed by the parametric Student's t-test. The islet granulation and exocrine invasion percentages and islet number were evaluated by the non-parametric Wilcoxon Rank-Sum test, whereas islet surface area was analyzed by the parametric Student's t-test. Differences between treated and untreated groups were considered significant at $p<0.05$. 
Table 1. Biochemical and morphometric data of treated and untreated C57BL/6J-ob/ob and C57BL/6J- $+/$ ? mice in Studies 1 and 2

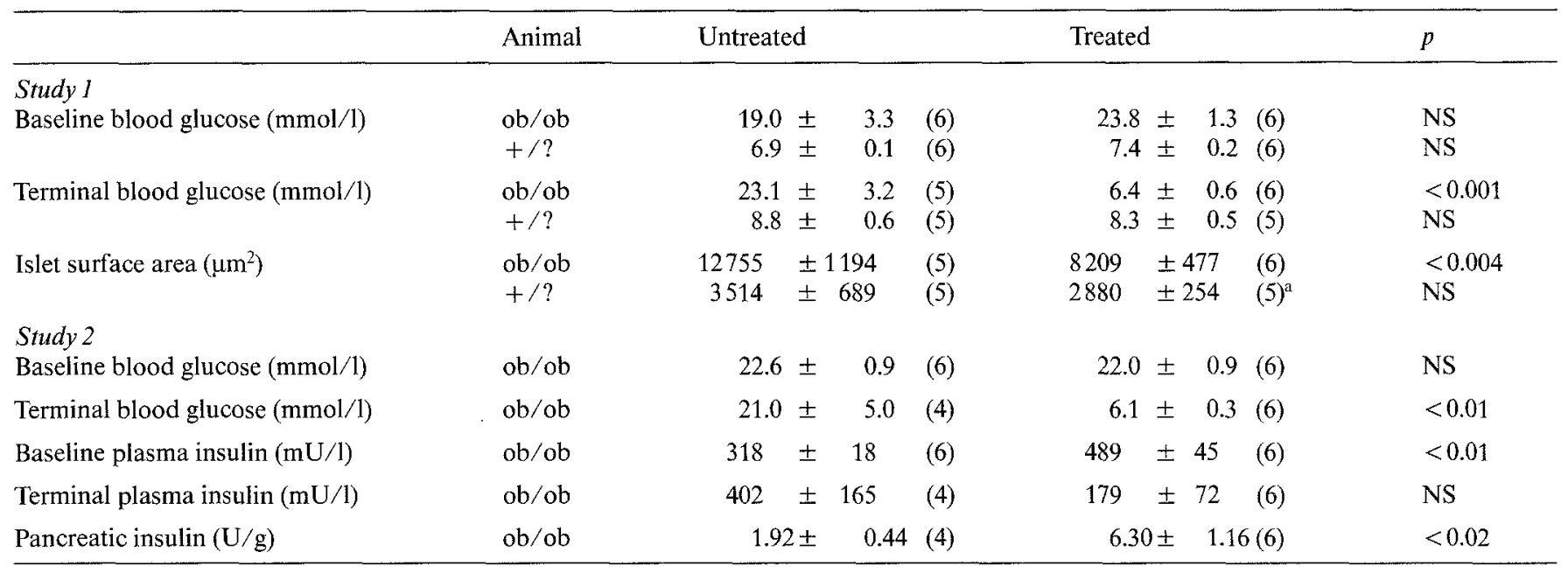

Number of animals is given in parentheses

The islet surface of treated $+/$ ? mice was significantly less than that of treated ob/ob mice $(p<0.001)$

Table 2. Biochemical data, percentage of granulated islets and islets with exocrine cells and islet number of treated and untreated C57BL/KsJ$\mathrm{db} / \mathrm{db}$ mice in Studies 3 and 4

\begin{tabular}{|c|c|c|c|}
\hline Measurement (units) & Untreated $\mathrm{db} / \mathrm{db}$ & Treated $\mathrm{db} / \mathrm{db}$ & $p$ \\
\hline \multicolumn{4}{|l|}{ Study 3} \\
\hline Baseline blood glucose $(\mathrm{mmol} / \mathrm{l})$ & $24.7 \pm 1.8$ & $22.1 \pm 1.4(5)$ & NS \\
\hline Terminal blood glucose $(\mathrm{mmol} / \mathrm{l})$ & $36.7 \pm 3.9(7)$ & $9.4 \pm 4.9$ & $<0.01$ \\
\hline Baseline plasma insulin $(\mathrm{mU} / \mathrm{l})$ & $287 \pm 66$ & $498 \quad \pm 81$ & NS \\
\hline Terminal plasma insulin (mU/l) & $32 \pm 6$ & $266 \pm 77$ & $<0.01$ \\
\hline Pancreatic insulin (U/g) & $0.52 \pm 0.11(7)$ & $5.39 \pm 1.23(5)$ & $<0.001$ \\
\hline \multicolumn{4}{|l|}{ Study 4} \\
\hline Baseline blood glucose $(\mathrm{mmol} / \mathrm{l})$ & $28.9 \pm 4.7$ & $29.5 \pm 2.2(6)$ & NS \\
\hline Average weekly blood glucose $(\mathrm{mmol} / \mathrm{l})$ & $36.5 \pm 0.8(6)$ & $18.6 \pm 4.9(6)$ & $<0.005$ \\
\hline Terminal blood glucose (mmol/s) & $40.9 \pm 3.1$ & $14.6 \pm 5.0(6)$ & $<0.001$ \\
\hline Islet number & $85 \pm 11$ & $213 \pm 35$ & $<0.03$ \\
\hline
\end{tabular}

Number of animals is given in parentheses

\section{Results}

\section{Study 1}

Blood glucose values for the $\mathrm{ob} / \mathrm{ob}$ and $+/$ ? mice are presented in Table 1 . At baseline, all ob/ob mice were similarly hyperglycaemic. Baseline levels of blood glucose were slightly above the euglycaemic range in all $+/$ ? mice. At termination, the blood glucose levels of treated ob/ob mice were significantly lower than those of untreated ob/ob mice, whereas they were unchanged in treated and untreated groups of $+/$ ? mice.

Pancreatic islet surface area measurements for the $\mathrm{ob} / \mathrm{ob}$ and $+/$ ? mice are reported in Table 1 . The islet surface area of treated ob/ob mice was significantly reduced in comparison with that of untreated ob/ob mice. Differences in islet surface area were not detected between the two groups of $+/$ ? mice. The islet surface of treated $+/$ ? mice was significantly less than that of treated ob/ob mice.

\section{Study 2}

The baseline and terminal blood glucose and plasma and pancreatic insulin content for treated and untreated $\mathrm{ob} / \mathrm{ob}$ mice are shown in Table 1. The blood glucose levels for both groups of ob/ob mice were similar to those in Study 1. The baseline plasma insulin of untreated and treated ob/ob mice was markedly elevated. At termination, treated ob/ob mice appeared to exhibit a reduction in plasma insulin compared with that of untreated $\mathrm{ob} / \mathrm{ob}$ mice. This depression in terminal plasma insulin was not statistically significant due to a large SEM. Pancreatic insulin content was significantly increased in treated compared with untreated ob/ob mice. 


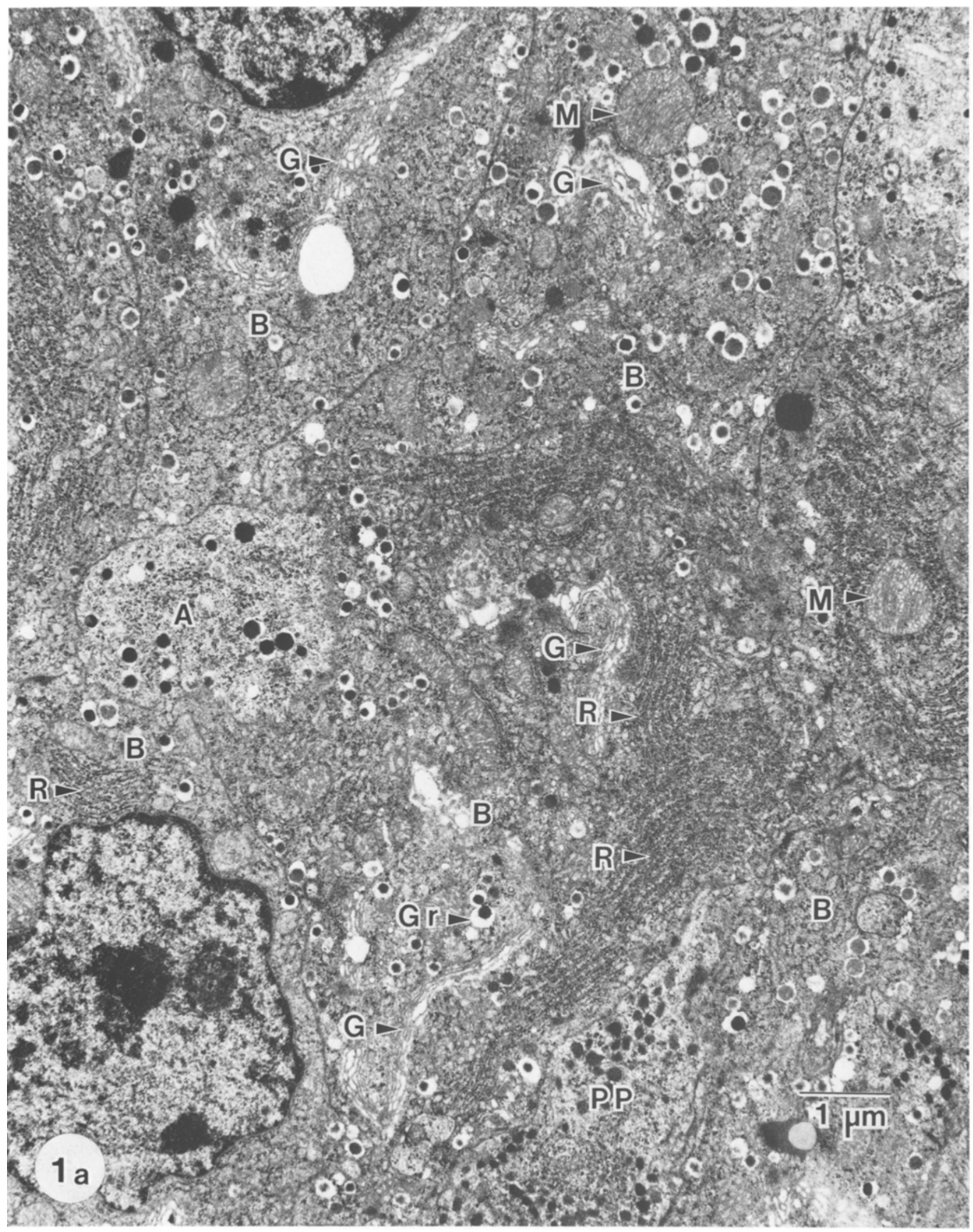

Fig. 1. Pancreatic islets from (a) untreated and (b) treated ob/ob mice. The $\beta$ cells (B) in Fig. 1a are markedly degranulated (Gr) compared with those which are heavily granulated (Gr) in Figure $1 \mathrm{~b}$. Note the expanded Golgi apparatus $(\mathrm{G})$, lamellar rough endoplasmic reticulum (R) and enlarged mitochondria (M) in Figure 1 a compared with the same unremarkable organelles in Figure $1 \mathrm{~b}$. In Figure $1 \mathrm{a}$, the $\alpha(\mathrm{A}), \beta$ (B) and probable pancreatic polypeptide (PP) cells are non-pathological. (Uranyl acetate and lead citrate; approximately $\times 13500$ ) 


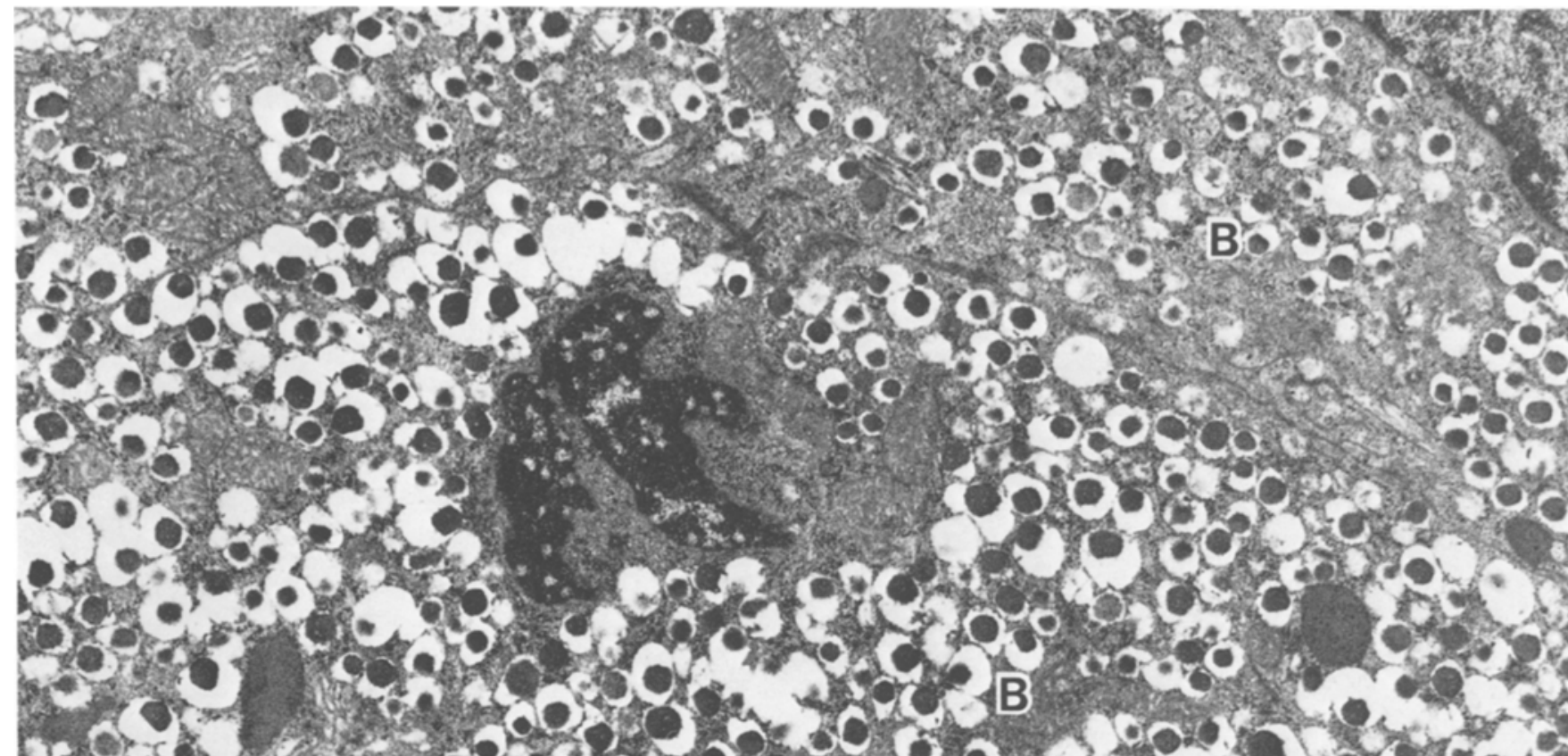
3. 5 . 3. G. 5., 2 a

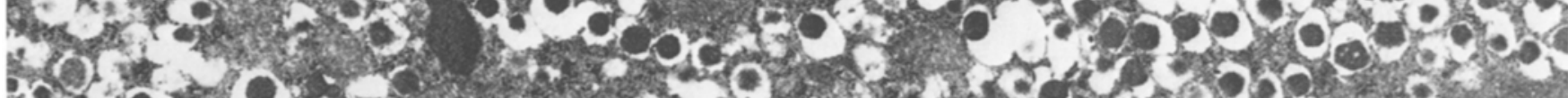

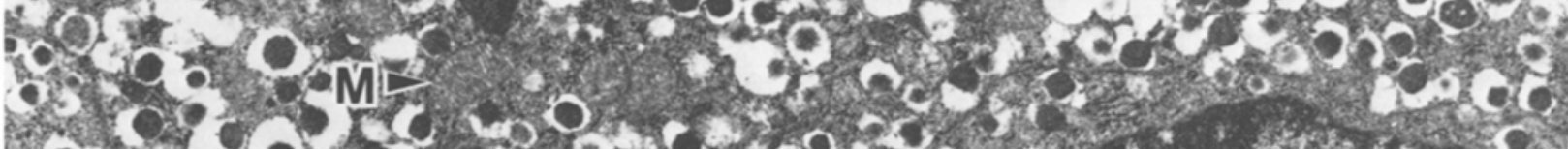

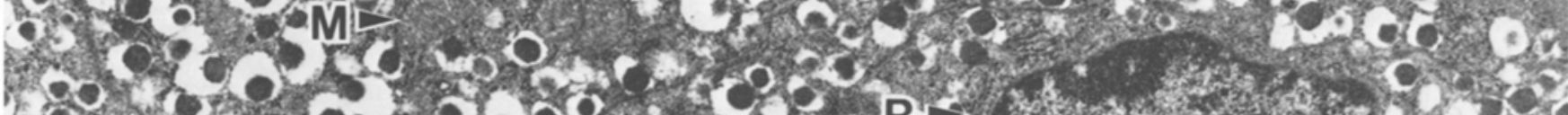

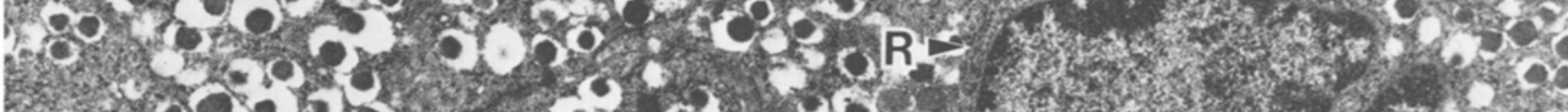

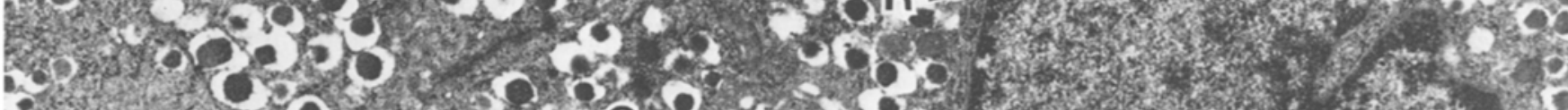

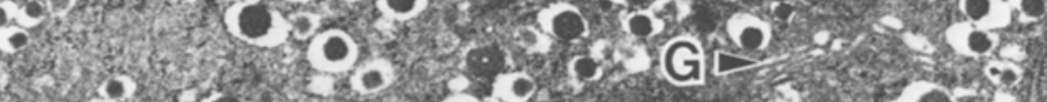

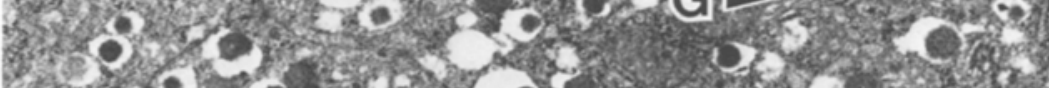

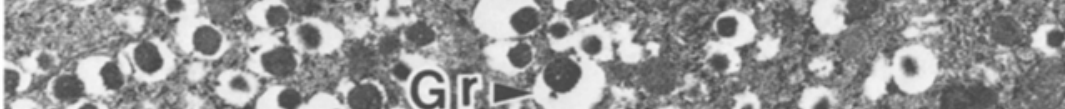

2. 5 .

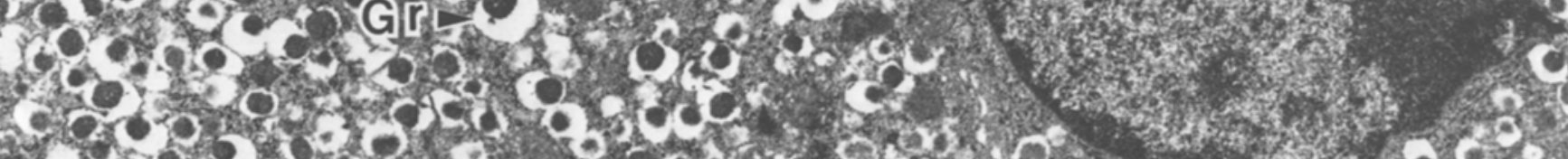

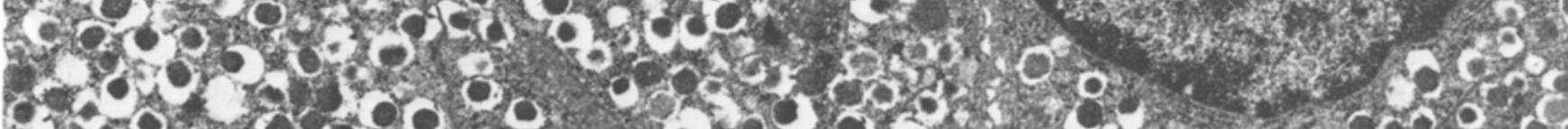
S.m. 3.

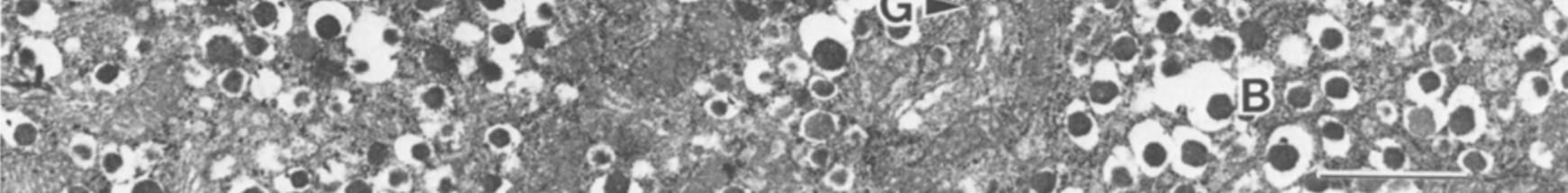
i.

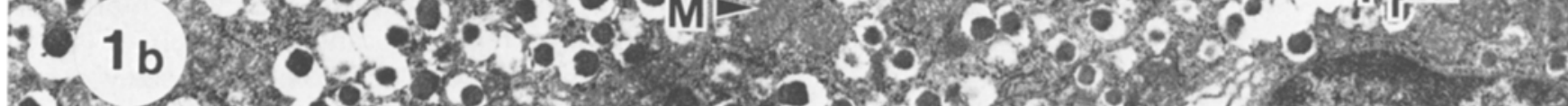

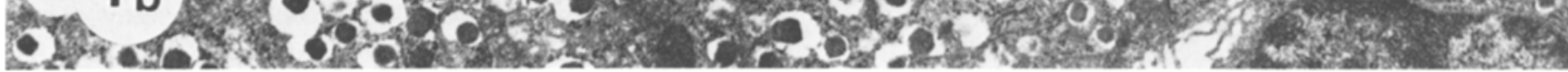



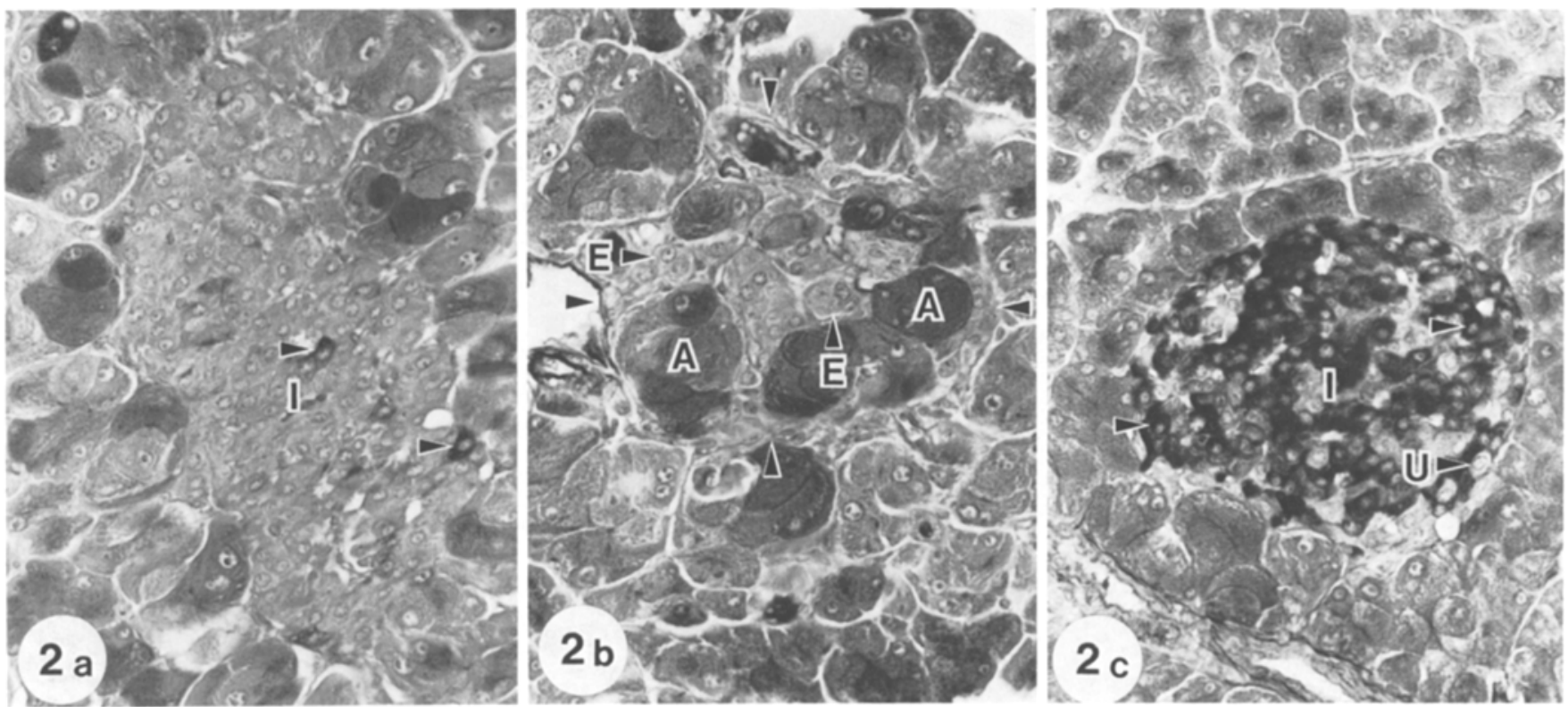

Fig. 2. Pancreatic islets (I) from (a, b) untreated and (c) treated $\mathrm{db} / \mathrm{db}$ mice. Although most of the B cells in Fig. 2 a are degranulated a few positive cells (arrowheads) are observable in the islet. Note the disorganization of the islet (Fig. 2b) which displays both acinar (A) and unstained endocrine cells (E). The probable outline of the islet (Fig. $2 \mathrm{~b}$ ) is indicated by arrowheads. Heavy $\beta$-cell granulation is evident in the islet on Fig. $2 \mathrm{c}$ (compare with Fig. $2 \mathrm{a}$ and b). Some $\beta$ cells (Fig. $2 \mathrm{c}$ ) are so heavily stained (arrowheads) that they are more conspicuous than juxtaposed granulated $\beta$ cells. The unstained elements (U) in the islet (Fig. 2 c) are probably $\alpha-, \delta$-and pancreatic polypeptide cells (aldehyde-fuchsin; approximately $\times 330)$

Under electron microscopy, most $\beta$ cells of untreated $\mathrm{ob} / \mathrm{ob}$ mice were characterized by moderate to severe degranulation (Fig. $1 \mathrm{a}$ ). In contrast, many of the $\beta$ cells of treated ob/ob mice displayed heavy granulation (Fig. 1b). The organelle population of $\beta$ cells of untreated obese mice exhibited definitive abnormalities. The rough endoplasmic reticulum was heavily distributed in the cytoplasm and frequently oriented in a lamellar configuration (Fig. 1a). The Golgi elements in $\beta$ cells of untreated $\mathrm{ob} / \mathrm{ob}$ mice appeared to be expanded (Fig. 1a) in comparison with those of treated obese mice. Some mitochondria were enlarged and contained densely packed cristae in certain $\beta$ cells of untreated obese mice (Fig. 1a). Overall, the ultrastructure of the $\beta$ cells of untreated ob/ob mice was indicative of a stressed pattern of synthesis and storage of insulin. Conversely, cytoplasmic organelles, such as the rough endoplasmic reticulum, Golgi apparatus and mitochondria appeared to be unremarkable in most $\beta$ cells of treated ob/ob mice (Fig. 1b). There was minimal ultrastructural evidence to indicate that these cells were stressed to synthesize and store insulin.

\section{Study 3}

The baseline, average weekly and terminal blood glucose and baseline and terminal plasma insulin for treated and untreated $\mathrm{db} / \mathrm{db}$ mice are presented in Table 2 . At baseline, both groups of mice displayed hyperglycaemia. However, during the course of the study and at termination, blood glucose was significantly depressed in treated compared with untreated $\mathrm{db} / \mathrm{db}$ mice. One of the treated $\mathrm{db} / \mathrm{db}$ mice showed continuous elevation of blood glucose throughout the study period $(27.5 \mathrm{mmol} /$ 1) and at termination $(28.9 \mathrm{mmol} / \mathrm{l})$. Both groups of mice were hyperinsulinaemic under baseline conditions. At termination the plasma insulin level was significantly greater in treated than in untreated $\mathrm{db} / \mathrm{db}$ mice.

The pancreatic insulin values and percentage of granulated islets and islets with exocrine cells for $\mathrm{db} / \mathrm{db}$ mice are also shown in Table 2 . In general, the pancreatic insulin content was markedly elevated in treated compared with untreated $\mathrm{db} / \mathrm{db}$ mice. However, the pancreatic insulin level was depressed $(0.875 \mathrm{U} / \mathrm{g})$ in the one treated $\mathrm{db} / \mathrm{db}$ mouse with continuous, high blood glucose. The islets from untreated $\mathrm{db} / \mathrm{db}$ mice displayed severe structural derangement and extensive degranulation of $\beta$ cells was observed (Fig. 2a). A majority of the examined islets of untreated $\mathrm{db} / \mathrm{db}$ mice was markedly disrupted and displayed a combination of acinar and endocrine cells (Fig. 2b) with the occasional presence of ductal elements. Overall, the morphology of islets of treated $\mathrm{db} / \mathrm{db}$ mice was unremarkable. On the basis of the aldehyde-fuchsin stain, the islets of treated $\mathrm{db} / \mathrm{db}$ mice displayed heavy granulation (Fig. $2 \mathrm{c}$ ). In fact, a few of the $\beta$ cells within some islets were so densely stained that they were more conspicuous than juxtaposed granulated $\beta$ cells (Fig. $2 \mathrm{c}$ ). The percentage of granulated islets was significantly greater in treated than in untreated $\mathrm{db} / \mathrm{db}$ mice. Although there was occasional displacement of a few exocrine cells into the endocrine tissue, the islets of treated $\mathrm{db} / \mathrm{db}$ mice appeared to be intact. It is of interest that the treated $\mathrm{db} / \mathrm{db}$ mouse which displayed consistent 
hyperglycaemia contained numerous degranulated and disrupted islets.

At the ultrastructural level, most of the $\beta$ cells of untreated $\mathrm{db} / \mathrm{db}$ mice consistently exhibited severe depletion of granules (Fig. 3 a). In contrast many of the $\beta$ cells of treated $\mathrm{db} / \mathrm{db}$ mice displayed moderate to heavy granulation (Fig. $3 \mathrm{~b}$ ). The organelles of most of the $\beta$ cells from untreated diabetic mice frequently showed severe abnormalities. The Golgi apparatus, rough endoplasmic reticulum and mitochondria were expanded (Fig. 3a) as described in Study 2. Probable lysosomes, indicative of early stages of necrosis, were prevalent in some $\beta$ cells of untreated diabetic mice (Fig. $3 \mathrm{a}$ ) and overall, the fine structure of the $\beta$ cells was compatible with a severely stressed pattern of synthesis and storage of insulin. In contrast, the cytoplasmic organelles in $\beta$ cells of treated $\mathrm{db} / \mathrm{db}$ mice showed minor derangement indicative of very mild stress. Moderate expansion of both the Golgi apparatus and rough endoplasmic reticulum was evident in some granulated $\beta$ cells of treated diabetic mice (Fig. 3 b).

Ultrastructural examination revealed that the islets of treated $\mathrm{db} / \mathrm{db}$ mice were richly supplied with $\beta$ cells as well as $\alpha-, \delta$ - and pancreatic polypeptide cells. On the other hand, the islets from untreated diabetic mice were scarce and contained a sparsity of $\beta$ cells. In fact, most islets from untreated $\mathrm{db} / \mathrm{db}$ mice displayed a predominance of $\alpha$-, $\delta$ - and pancreatic polypeptide cells with displacement of exocrine cells among the endocrine cells.

\section{Study 4}

The baseline, average weekly and terminal blood glucose and relative estimate of islet number for treated and untreated $\mathrm{db} / \mathrm{db}$ mice are illustrated in Table 2. Under baseline conditions, both these groups of mice were markedly hyperglycaemic. For the duration of the study and at termination, the blood glucose levels of treated $\mathrm{db} / \mathrm{db}$ mice were significantly depressed in comparison with those of the untreated diabetic mice. Two of the treated $\mathrm{db} / \mathrm{db}$ mice showed continuous elevation of blood glucose throughout the study period (32.2 and $35.0 \mathrm{mmol} / \mathrm{l})$ and at termination $(33.7$ and $26.5 \mathrm{mmol} /$ 1). The quantity of pancreatic islets was significantly greater in treated than in untreated $\mathrm{db} / \mathrm{db}$ mice. Most of the islets which were counted in pancreases of untreated diabetic mice were atrophic. In contrast, degenerate islets were rarely encountered in pancreases of treated $\mathrm{db} / \mathrm{db}$ mice, except in the two who displayed continuous elevation of blood glucose during the study.

\section{Discussion}

In the present study, chronic treatment with ciglitazone produced marked regranulation of $\beta$ cells in pancreatic islets of treated ob/ob and $\mathrm{db} / \mathrm{db}$ mice. This restoration of $\beta$-cell granulation was supported by correlative biochemical data which showed a significant increase in pancreatic insulin content in the islets of these treated mice. The microscopic and biochemical data are also in accord with previous light microscopic findings [1] which demonstrated that regranulation of islets had occurred in ob/ob mice after prolonged treatment with ciglitazone. Regranulation of $\beta$ cells has also been reported to occur in insulin-resistant mice after treatment with oxytetracycline [7] and low doses of alloxan [8,9]. However, since oxytetracycline is also efficacious in insulinopenic animal models $[10,11]$, it probably has a different mode of action in comparison with that of ciglitazone which is not active in insulin-deficient animals [1]. In the current investigation, the regranulation of $\beta$ cells may be the indirect result of improved insulin sensitivity [1] and lowered plasma glucose. In other words, since the demand for circulating insulin is alleviated $[2$, $3]$, the $\beta$ cells were able to synthesize efficiently and store insulin via a feedback mechanism. This theory is reinforced by the fact that the $\beta$ cells of treated ob/ob and $\mathrm{db} / \mathrm{db}$ mice were heavily granulated without extensive proliferation of the rough endoplasmic reticulum and Golgi apparatus. It is also conceivable that ciglitazone may have a direct effect on the $\beta$ cells of ob/ob and $\mathrm{db} / \mathrm{db}$ mice by inhibiting insulin release or by some other unknown mechanism of action.

On the basis of the current study, significant regranulation of $\beta$ cells was identified in the pancreatic islets of treated ob/ob and $\mathrm{db} / \mathrm{db}$ mice. Therefore, it is conceivable that this compound may have an analogous mechanism of action in these two obese, hyperglycaemic mouse models. However, it should be pointed out that despite the regranulation, ultrastructural evidence of $\beta$-cell stress, such as moderate proliferation of the Golgi apparatus and rough endoplasmic reticulum, were confined to treated $\mathrm{db} / \mathrm{db}$ mice. Furthermore, persistent, mild hyperglycaemia was observed in the treated $\mathrm{db} / \mathrm{db}$ mice. On the contrary, pancreatic $\beta$ cells rarely displayed hypertrophic organelles and hyperglycaemia was not identified in ob/ob mice after treatment with ciglitazone. These data suggest that ciglitazone may be a more efficacious agent in the C57BL/6J-ob/ ob mouse with a mild diabetic background than in the severely diabetic C57BL/KsJ-db/db mouse [12-15].

In an earlier, non-systematic morphological study, the results suggested that ciglitazone treatment of ob/ ob mice induced a reduction in surface area of pancreatic islets [1]. Definitive support for this observation is provided by the current systematic, morphometric study which showed that treated ob/ob mice displayed smaller islets than those of untreated ob/ob mice. Due to the fact that hyperplasia and hypertrophy of islets have been documented in ob/ob mice of the C57BL/6J genetic background $[12,16]$, it is logical to hypothesize that ciglitazone may have affected islet size by interruption of these abnormal processes. The islet surface area of treated $\mathrm{C} 57 \mathrm{BL} / 6 \mathrm{~J}-+/$ ? mice (lean littermates of ob/ 


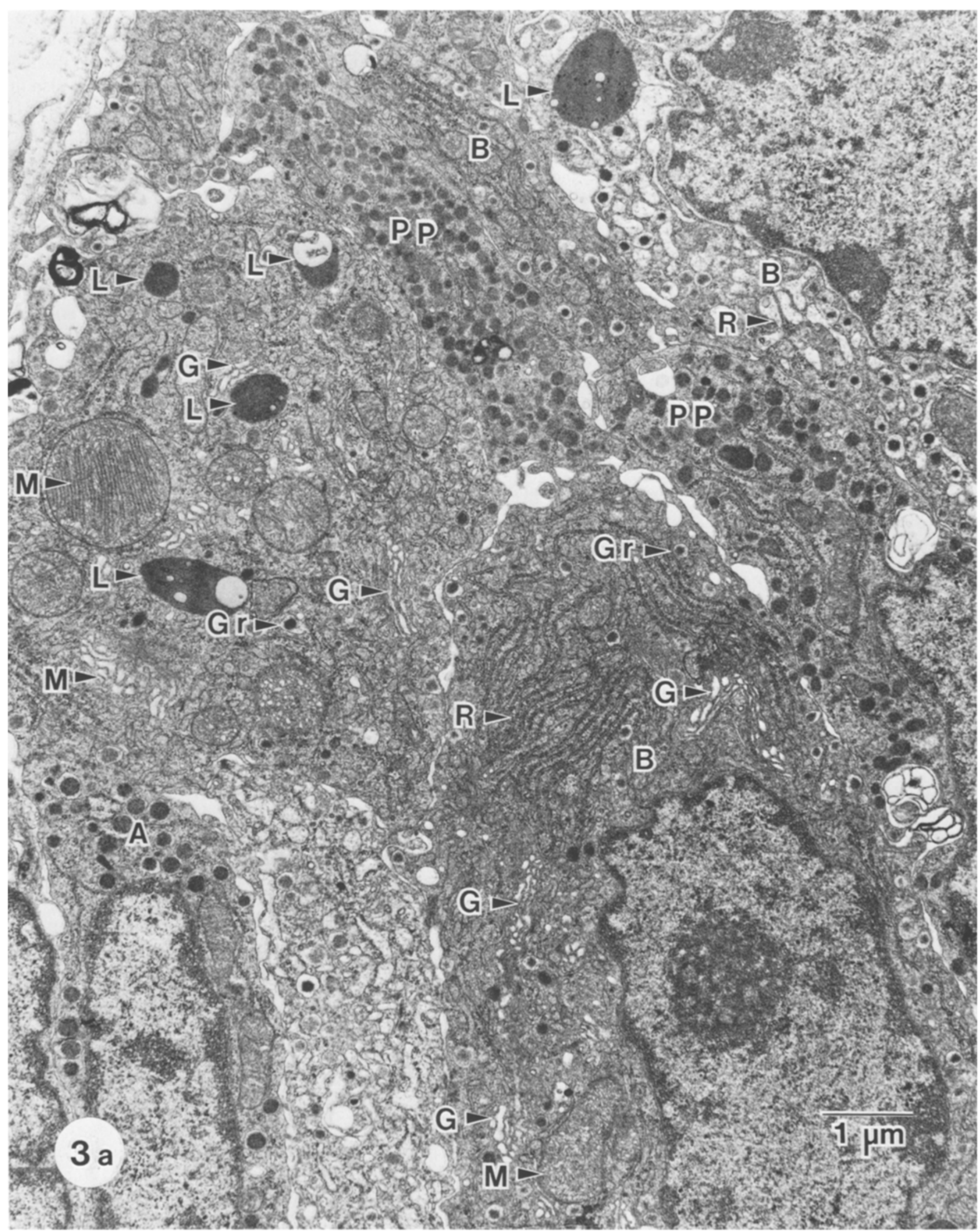

Fig. 3. Pancreatic islets from (a) untreated and (b) treated $\mathrm{db} / \mathrm{db}$ mice. The $\beta$ cells (Fig. 3 a) display a sparsity of granules (Gr), expanded Golgi apparatus $(\mathrm{G})$, proliferative rough endoplasmic reticulum $(\mathrm{R})$ and some enlarged mitochondria (M). The $\beta$ cells (Fig. $3 \mathrm{~b}$ ) are more heavily granulated $(\mathrm{Gr})$ with mild expansion of the Golgi apparatus $(\mathrm{G})$ and rough endoplasmic reticulum $(\mathrm{R})$. Note the aggregation of lysosomes $(\mathrm{L})$ in the $\beta$ cell at the left of Fig. $3 \mathrm{a}$ and the dilated rough endoplasmic reticulum (R) in the $\beta$ cell at the upper right of Fig. $3 \mathrm{a}$. The $\alpha(\mathrm{A}), \beta$ (B) and probably pancreatic polypeptide (PP) cells are unremarkable in Fig. 3 a. (Uranyl acetate and lead citrate; approximately $\times 15300$ ) 


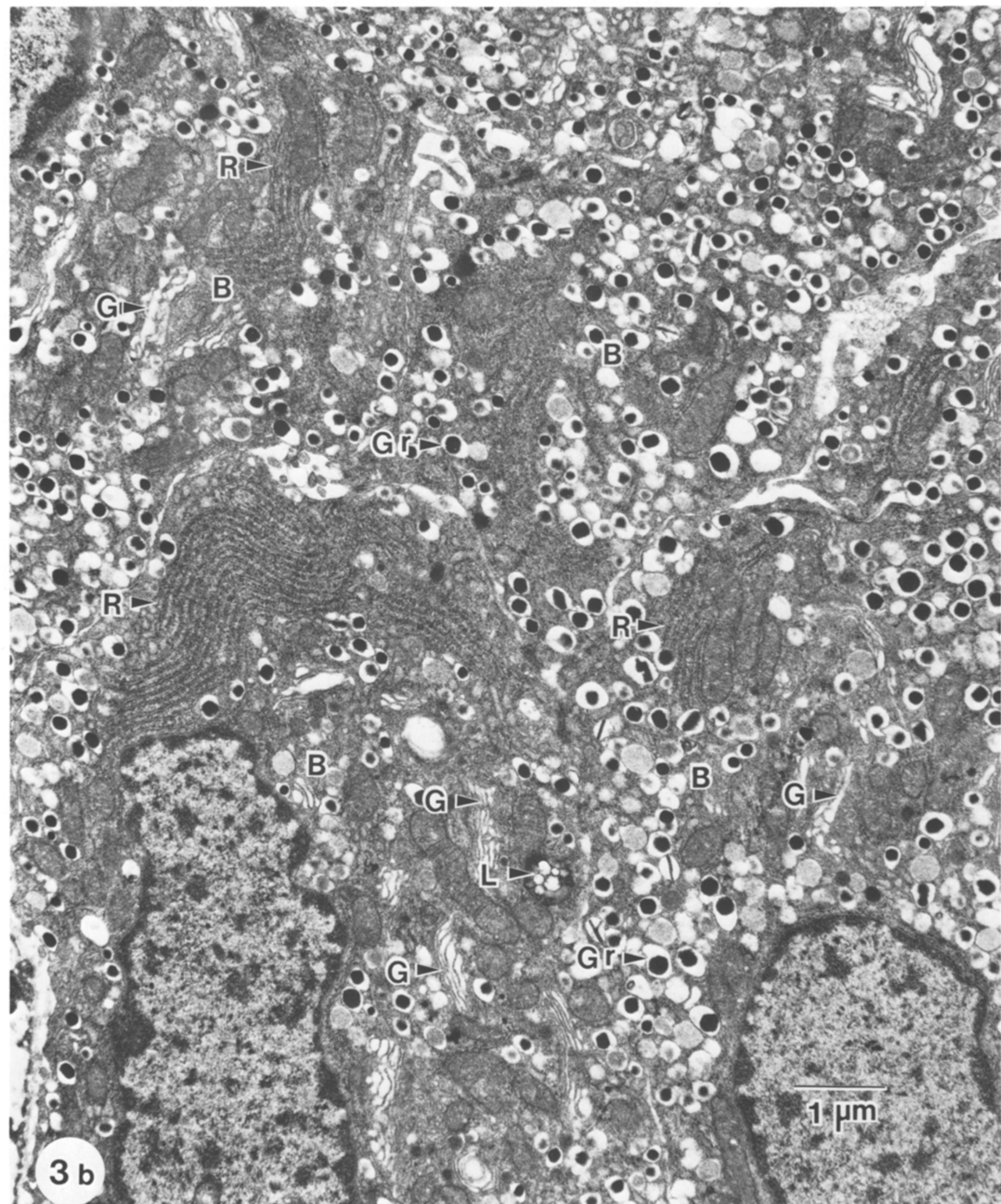


ob mice) was significantly less than that of the treated $\mathrm{ob} / \mathrm{ob}$ mice. This finding suggests that the progression of islet enlargement in treated ob/ob mice was arrested or slowed but not to the level of their lean littermates by ciglitazone intervention at 7-8 weeks of age. These morphometric data on islet surface area are also in accord with earlier studies which showed that the pancreatic insulin content was lower in treated $+/$ ? mice than in treated ob/ob mice [1]. Since the islet expansion of untreated ob/ob mice begins at the onset of obesity, future studies should focus on ciglitazone treatment of younger (4-5 weeks old) ob/ob mice in an effort to prevent the development of this disorder.

It appeared that ciglitazone maintained the structural integrity of islets in most of the treated $\mathrm{db} / \mathrm{db}$ mice and restricted infiltration of exocrine cells into the endocrine tissue. Since the process of exocrine cell invasion has been reported to be involved in the degeneration of islets in untreated $\mathrm{db} / \mathrm{db}$ mice $[12,17-20]$, it is conceivable that ciglitazone may prevent degradation and loss of islets in this animal model. Definitive support for this hypothesis stems from the morphometric data which show that the relative number of pancreatic islets was significantly greater in treated than in untreat$\mathrm{ed} \mathrm{db} / \mathrm{db}$ mice. Due to the fact that a direct comparison was not made, it is unknown if ciglitazone-treated $\mathrm{db}$ / $\mathrm{db}$ mice contain the same quantity of pancreatic endocrine tissue as their lean littermates. Nonetheless, it is still highly significant that the number of islets in the treated $\mathrm{db} / \mathrm{db}$ mice was apparently sufficient to prevent hypoinsulinaemia. This observation was substantiated by the marked increase of plasma and pancreatic insulin in treated compared with untreated $\mathrm{db} / \mathrm{db}$ mice. Since the current studies involved treatment periods of 9 and 20 weeks, it would be relevant to determine whether islets of $\mathrm{db} / \mathrm{db}$ mice remain non-pathological with prolonged administration of ciglitazone. Furthermore, future studies should concentrate on 4-5 week old $\mathrm{db} / \mathrm{db}$ mice to determine whether hyperinsulinaemia, hyperglycaemia and islet complications can be prevented by early treatment with ciglitazone.

Acknowledgements. The authors wish to thank L. Rogers for typing this manuscript as well as the Histology Laboratory, Pathology-Toxicology Unit, The Upjohn Company for the serial sectioning of pancreatic tissue.

\section{References}

1. Chang AY, Wyse BM, Gilchrist BJ, Peterson T, Diani AR (1983) Ciglitazone, a new hypoglycemic agent. I. Studies in ob/ob and $\mathrm{db} / \mathrm{db}$ mice, diabetic Chinese hamsters, and normal and streptozotocin-diabetic rats. Diabetes 32: 830-838

2. Chang AY, Wyse BM, Gilchrist BJ (1983) Ciglitazone, a new hypoglycemic agent. II. Effect on glucose and lipid metabolisms and insulin binding in the adipose tissue of $\mathrm{C} 57 \mathrm{BL} / 6 \mathrm{~J}-\mathrm{ob} / \mathrm{ob}$ and $-+/$ ? mice. Diabetes 32: 839-845

3. Chang AY, Gilchrist BJ, Wyse BM (1983) Ciglitazone, a new hypoglycaemic agent. 3. Effect on glucose disposal and gluconeogenesis in vivo in the $\mathrm{C} 57 \mathrm{BL} / 6 \mathrm{~J}-\mathrm{ob} / \mathrm{ob}$ and $-+/$ ? mice. Diabetologia $25: 514-520$

4. Lloyd B, Burrin J, Smythe P, Alberti KGMM (1978) Enzymic fluorometric continuous-flow assays for blood glucose, lactate, pyruvate, alanine, glycerol and 3-hydroxybutyrate. Clin Chem 24: 1724-1729

5. Zaharto DS, Beck LV (1968) Studies of a simplified plasma insulin immunoassay using cellulose powder. Diabetes 17:444-457

6. Chang AY, Noble RE, Wyse BM (1977) Streptozotocin-induced diabetes in the Chinese hamster. Biochemical and endocrine disorders. Diabetologia 13: 596-602

7. Begin-Heick N, Heick HM, Norman MG (1979) Regranulation of islets of Langerhans and normalization of in vivo insulin secretion in ob/ob mice treated with oxytetracycline. Diabetes 28: 65-70

8. Mahler RJ, Szabo O (1971) Amelioration of insulin resistance in obese mice. Am J Physiol 221: 980-983

9. Solomon J, Bulkley RJ, Mayer J (1974) Effect of a low dose of alloxan on blood glucose, islet beta cell granulation, body weight and insulin resistance of ob/ob mice. Diabetologia 10: 709 715

10. Dalpe-Scott M, Heick HMC, Begin-Heick N (1982) Oxytetracycline treatment improves the response to insulin in the spontaneously diabetic (BB) rat. Diabetes 32:53-59

11. Hiatt $N$, Bonorris $G(1970)$ Insulin response in pancreatectomized dogs treated with oxytetracycline. Diabetes 19:307-311

12. Coleman DL, Hummel KP (1973) The influence of genetic background on the expression of the obese (ob) gene in the mouse. Diabetologia 9: 287-293

13. Boquist L (1977) Differences in the expressions of spontaneous and induced diabetes in Chinese hamsters, Mongolian gerbils and C57BL/KsJ and C57BL/6J mice. Int Congr Ser Excerpta Medica 413: 683-690

14. Hummel KP, Coleman DL, Lane PW (1972) The influence of genetic background on expression of mutations at the diabetes locus in the mouse. I. C57BL/KsJ and C57BL/6J strains. Biochem Genet 7: 1-3

15. Boquist L, Hellman B, Lernmark A, Taljedal IB (1974) Influence of the mutation 'diabetes' on insulin release and islet morphology in mice of different genetic backgrounds. J Cell Biol 62: 77-89

16. Bactens D, Stefan Y, Ravazzola M, Malaisse-Lagae F, Coleman DL, Orci L (1978) Alteration of islet cell populations in spontaneously diabetic mice. Diabetes 27:1-7

17. Hummel KP, Dickie MM, Coleman DL (1966) Diabetes, a new mutation in the mouse. Science 153: 1127-1128

18. Coleman DL, Hummel KP (1967) Studies with the mutation, diabetes, in the mouse. Diabetologia 3: 238-248

19. Like AA, Chick WL (1970) Studies in the diabetic mutant mouse: I. Light microscopy and radioautography of pancreatic islets. Diabetologia $6: 207-215$

20. Like AA, Chick WL (1970) Studies in the diabetic mutant mouse: II. Electron microscopy of pancreatic islets. Diabetologia 6: $216-242$

Received: 30 November 1983

and in revised form: 26 April 1984

Arthur R. Diani, Ph. D.

Diabetes and Gastrointestinal Disease Research

The Upjohn Company

301 Henrietta Street

Kalamazoo

Michigan 49001

USA 